\title{
Research on Emotion Expression in the Form Design of Daily Products
}

\author{
Yao Shanliang, Man Luo* \\ Wuhan engineering university art and design institute \\ Wuhan city, Hubei province
}

\begin{abstract}
Through the analysis of emotional expression of form design in the daily-use products, the paper further explores the essence of form design, as well as the characteristics of the elements of the form of products and the development of dailyuse products. Finally, it is concluded that the daily product form design that meets the real needs and emotional needs of consumers should be based on user's cultural characteristics and regional habits and lifestyle to give the users an emotional experience.
\end{abstract}

\section{Keywords—Romantic; Daily products; Form design}

\section{INTRODUCTION}

From a certain point of view that human history can be seen as a history of creation, humans make production in the process of survival to meet their food, clothing and tools, daily products is closely associated with people from the start, it is to solve the problems of the People's Daily life and meet the demand of life. The origin of the form can be traced back to the Stone Age of mankind, beginning with the earliest totem, recording People's Daily life and displaying people's mental state. Form design is modern, regional and symbolic, but now many of the commodity products, although has the cool modelling and good function, lack of warm, such products can not bring profound experience to users, only fully research regional culture, lifestyle, aesthetic habits, to make the daily product form designing that is more delicate, eventually conforms to our country consumer satisfy the real demand for daily-use products and emotions.

\section{OVERVIEW OF DAILY PRODUCT DESIGN.}

Daily products are closely related to People's Daily life. It is designed to solve and facilitate the normal operation of daily life for people [1]. Unlike other products, it has a close relationship with people, thus plays a crucial role in modern design, besides before the concept of the ancient design.

In primitive society, people made tools to meet the daily necessities of life based on the needs of daily life. In the Stone Age, although manufacturing skills and the way is very limited, because of commodity products, designers, manufacturers and users for the same subject, thus in the process of design and manufacture is not exist on the exchange and communication with distortion and misleading problem, so the final product effect is the most accord with the actual demand, consumer and commodity products, form the most conform to the requirements of the function.
Along with the social development and progress, farming civilization formed, the development of handicraft industry, continuously strengthen the feudal monarchy, based on the stability of the social division of labor, in the process of service for the upper nobility, custom service began to appear in producers and users both began to communicate with each other, which let technology and design more harmony on the product. That the service object is the upper aristocracy, according with their status and status of the need to start, also appeared the decoration meaning. That point in the history of Chinese and western design are reflected, such as our country ancient times has the branch of official kiln and folk kiln, kiln firing porcelain for the palace, production technology and strictly confidential, craft exquisite, in western rococo period, no longer constrained at Versailles palace life, art style is shift, and by the court gradually penetrated into the upper society.

After the industrial revolution, mechanization and mass production replaced handicrafts, industrial products replaced handicrafts, and the positioning of daily products was changed from the previous heavy decoration to focus on functions. Then the relationship between users' demand and production rationality reach a balance daily-used products form to the user's rational balance between, with the appearance of new technology and material, daily-use products form more forms into a real possibility, and daily product form from the original single relatively diversified development to today's [2].

Information age arrival, the design of new changes have taken place in the form of essential connotation and denotation, which makes the industrial revolution after the formation of the design method, the concept, principles, also changed to some extent, different from the past through a single commodity products, to meet the needs of most consumers. In today's advanced digital and network technology, make a design group is more detailed and accurate positioning, to adapt to the constantly changing consumer emotional needs and personality, such design, production, and formed a new relationship between customers, daily-use products increasingly subdivided market, by the few varieties by great quantity, small batch, diversified direction.

Whatever before or after the industrial revolution, people's attention to daily products has been focused on functions, forms, styles and so on. But when accumulated to a certain extent, the material conditions in diversity and information highly developed modern society, the modernist daily product form can no longer meet people's needs, people for the spiritual level and the quality of life and the details will have higher requirements, so demand for daily-use products is not only a 
function, even more about emotional needs, commodity products, paying attention to emotional care is very important.

\section{MORPHOLOGICAL DESIGN AND ITS CHARACTERISTICS.}

Form is the first element in conveying the purpose and intention of design [4], it mainly through the product dimension, shape, scale and influence psychological experience of hierarchical relationships to users, makes people wonder, joy, and wondered, meet, relaxed, confusion and so on, all kinds of psychological mood, as a result, form is the expression of design factors.

The origin of form design with human production, ancient ancestors will draw the totem is the embodiment of mythical images, from all the elements of a product form, form design has such features timely, regional, and symbolic.

\section{A. Timely}

Aesthetic characteristics and the value orientation of people from different ages and the emergence of new materials, new technology will affect the product's form, as Goethe said, "the influence of the times on the people at that time is very great."[5] Such as the end of world war ii, many of the new plastic material was developed, because of its high strength, good toughness characteristics is widely used in products, thus forming the unique "plastic age design style" of the 20th century.

\section{B. Regional}

Regional unique cultural consciousness and aesthetic consciousness through the inherent to the product form, the form of many ethnic minorities in China and north American indigenous peoples clothes, designs are in the form of inherent convey their local habits of cultural connotation and the characteristic, aesthetic, religious, and contains the function.

\section{Symbolic}

Whether it is the handicraft before the industrial revolution or the modern industrial product after the industrial revolution, it is created and used by human beings, and thus has the value, spirit and significance endowed by mankind. It includes the cultural atmosphere, social environment and its influence behind the form. (1)The symbolic meaning of color is that different cultures represent different cognition. In ancient China, yellow symbolizes power and dignity while in the west it is a symbol of humiliation. Red in the east symbolizes auspiciousness, while in the west, it means struggle and sacrifice. Purple is a symbol of nobleness and power in western religions, but it is a taboo color in Islamic countries. In the ancient times, it was often used in the autumn to collect and execute prisoners. In contrast to red, it was a bloodless and lifeless expression, symbolizing death, and the west considered white noble and elegant, symbolizing innocence.(2) The material of the symbolic, it is an important part of constitute the product configuration, different material and texture will bring different visual and tactile experience to the product, for example, wood, bamboo is often brings plain, natural and human feelings; Glass is a symbol of transparency, refreshing, stainless steel is a symbol of technology. (3)The symbolism of the structure is different from that of the symbol and cognition of the structure proportion. The Chinese and western countries have different perceptions, and the Chinese architecture is symmetrical and imposing in the central axis. And the western gothic architecture pursues spiritual rise and purification. The west has a strict demand for the golden ratio, and China is making intuitive sense. (4) The symbolic of modeling, the symbol of product modeling can reflect gender language, such as product modelling outline most men mix present a straight line and curve, surface and interfacial transition between abrupt, angular; For the female design product, the outline basically adopts the graceful curve, the turning point between the surface and the surface is the arc, the transition is natural and round.

\section{EMOTIONAL EXPRESSION OF THE FORM DESIGN OF DAILY PRODUCTS.}

\section{A. Emotional expression based on behavior}

Nordic design has always advocated the democratic design idea, design model of the Swedish furniture design like democracy and its manufacturer "ikea", consumers in the ikea is experiential way of shopping, the label on the product and advertising system will tell people how to shopping, buy and not followed by consumers, affect the consumer's shopping experience [6]. Northern Europe is a long day short area, people live in the long and cold night, the color of products, the shape to bring bright, comfortable, security. Series of ceramics for daily use products such as Finnish architect frank design "Kilta", some of its spare parts use the natural material such as plug, the cane makes up wooden log apply embodies the tradition of the Nordic design, the stacked convenient and bowl cover the buckle cover structure, as well as a variety of glaze color for different levels of consumer choice, the choice of these detail design to meet the real needs of People's Daily life, took into account the national habits, living environment and aesthetic tradition.

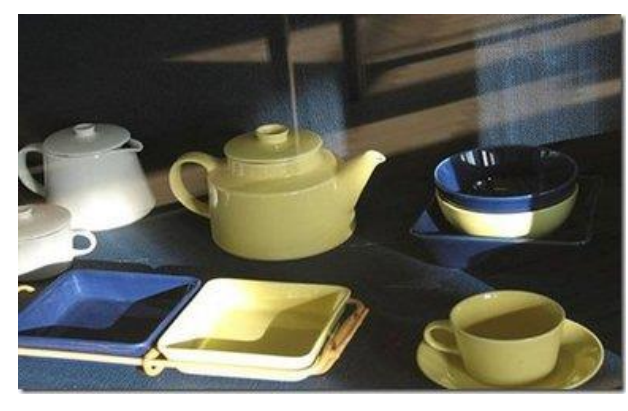

Fig. 1. kai frank: Kilta.

\section{B. Emotional expression based on perception.}

Everyone has their own unique cognitive sensory systems of the world, people rely on such as vision, touch, hearing to feel cold, warm, dizziness, ringing, etc., at the same time these feelings can lead to a corresponding psychological experience, such as warm, cheerful, bright, cold, dizziness accompanied with sad and painful. The color in daily products can bring the intuitive emotional experience, the light and shade of daily products, through the visual perception of people to bring different emotional experience. At present, some new 
technologies will be applied in daily product design to express the designer's personality pursuit and emotional transmission.[8], such as Japanese fashion designer Kosuke Tsumura Hair transplant technology applied to traditional Japanese lantern, lantern's surface is covered by hair, light shone through the pores on the skin can see very clear, giving a person experiences a little creepy, without regarding of personal interest, Kosuke Tsumura's lantern is designed by stimulating way to express feelings.

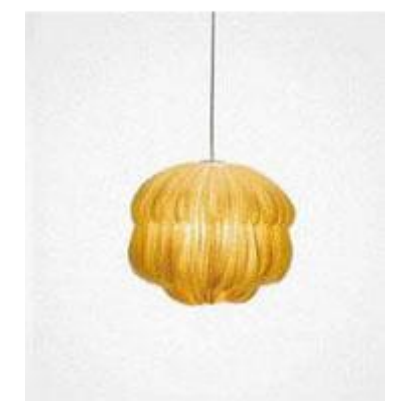

Fig. 2. Tama village: Kami Tama.

\section{Emotional expression based on thinking mode.}

The form of a daily product can make a person consciously or unconsciously associate something with something or a scene, thus generating thinking and attaining emotional resonance [10]. This emotional expression, however, is uncertain, because users have different background, level of education, social experience, gender and personality differences, therefore, in the face of the same commodity products, while experiencing different emotional experience. The application of form design in daily products is not only to imitate the material and color, but also to arouse the memory of the vast majority of people, so that it can have a wide resonance. For example, the product designer's classic fruit juice box design, the banana juice box with the familiar teapot, it is just the soft corner of the box opening to make a green feel like the end of the banana top. It is the creation and design of the unique features of this series of themes. The series also includes the kiwi juice box, which is attached to the paper with a flocking technique that makes the box look like the skin of a kiwi. In the application of morphological design, the subtle differences between memory and reality are emphasized to arouse the user's thinking and achieve the purpose of emotional expression.

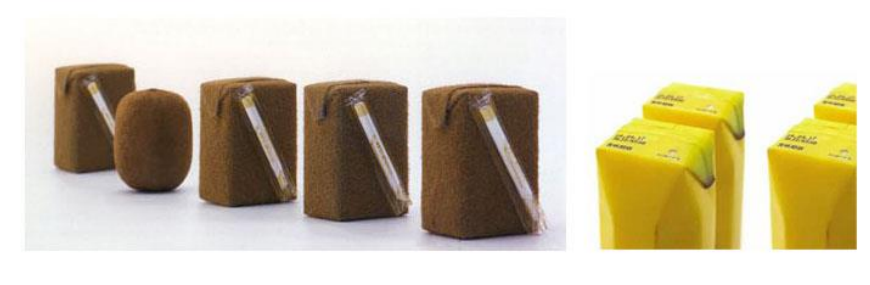

Fig. 3. Direct person: the skin of juice.

\section{CONCLUSION}

Daily products is closely related to people's lives, national daily-used products on the design includes the ethnic cultural habits and characteristics, analysis of the daily product form design in the way of emotional expression, which is of great significance to the development of China's commodity products. In modern commodity products, design, on the one hand, paying attention to the form design of regionality, times and symbolic, which reflects the product itself conveys meaning, has created a culture brings the user's psychological feelings, thus in the perception level to realize products for their own meaning; To express daily products, on the other hand, the intrinsic relationship between content and form, into the designer personal feelings and the national spirit, let form design in daily product design be better conveyed.

\section{REFERENCES}

[1] Shen Tianyu, Chen foam. Analysis of daily products from nature [J]. Packaging engineering, 2012.

[2] Zhao Zhengqiang. Value composition of commodity design [J]. Packaging engineering, 2015.

[3] Hangzhou. The democratic spirit of design [J]. Decoration, 2010.

[4] Meng Xiangbin. Loan of packaging form design [J]. Packaging engineering, 2015.

[5] Huang Lingyu, wang zeng. Research on modern product form design [J]. Packaging engineering, 2010.

[6] Liu qing. Design of dialyzed emotional design from northern Europe in daily products [J]. Packaging engineering, 2011.

[7] Peng Guohua, Chen hongjuan, Yang junshun. Visual experience and daily product design [J]. Packaging engineering, 2015.

[8] Original research. Design of the design [M]. Zhu, translated. Jinan: shandong people's publishing house, 2006.

[9] Wang Yushan, li shiguo. Value and application of emotional memory in interactive design [J]. Packaging engineering, 2011.

[10] Zhang Daoyi. Historical mission of design art [J]. Journal of nanjing art institute, 2010. 